DOI: $10.17058 /$ rjp.v5i2.5710

\title{
O PAPEL DO ESTADO E DA SOCIEDADE CIVIL NA ELABORAÇÃO DOS PLANOS ESTRATÉGICOS DE DESENVOLVIMENTO: O CASO DOS CONSELHOS REGIONAIS DE DESENVOLVIMENTO CELEIRO E NOROESTE COLONIAL ${ }^{1}$
}

\author{
Danieli Grandotto Felipim ${ }^{2}$ \\ Caroline da Rosa ${ }^{3}$ \\ Vinícius Ribas Samuel dos Santos ${ }^{4}$ \\ Sérgio Luís Allebrandt ${ }^{5}$
}

\begin{abstract}
RESUMO
O objetivo deste estudo foi analisar o processo de construção dos planos estratégicos de desenvolvimento nos Conselhos Regionais de Desenvolvimento (Coredes) Celeiro e Noroeste Colonial, descrevendo e analisando a dinâmica de participação da sociedade e do Estado nesses processos. $\mathrm{O}$ estudo enquadra-se como pesquisa interpretativa e qualitativa. Como estratégia metodológica, foram utilizadas pesquisa bibliográfica, pesquisa documental e entrevistas narrativas com atores sociais e agentes públicos e privados da região. Criados no início da década de 1990, os Coredes têm, entre os seus principais objetivos, o de formular e executar estratégias regionais, consolidando-as em planos de desenvolvimento regional. Com a realização do estudo, constatou-se que ambos os Coredes apresentaram fragilidades na elaboração de seus planos. Da mesma forma, as entrevistas realizadas apontam para a necessidade de realização de um novo pacto regional antes da atualização dos atuais planos, se as regiões efetivamente quiserem assumir o processo e o seu resultado em todas as suas fases, especialmente nas de implementação e efetiva concretização.
\end{abstract}

Palavras-chave: Desenvolvimento Regional. Planejamento Estratégico. Participação social. Sociedade civil. Conselhos Regionais de Desenvolvimento.

\begin{abstract}
The objective of this study was to analyze the process of building of strategic development plans in the Regional Councils of Development (Coredes) Celeiro and Noroeste Colonial, describing and analyzing the dynamics of participation by society and the State in these processes. The study classifies itself as interpretative and qualitative research. As methodological strategy, it was used bibliographical research, documentary research and narrative interviews with social actors and public and private actors in the region. Created in the early 1990s, the Coredes have among its main objectives to develop and implement regional strategies, consolidating them into regional development plans. With the

\footnotetext{
${ }^{1}$ O presente artigo é uma nova versão condensada de dois capítulos do livro Observando o Planejamento regional no Rio Grande do Sul: uma análise da experiência recente dos Conselhos Regionais de Desenvolvimento (Coredes), publicado pela EDUNISC em 2015.

${ }^{2}$ Aluna do Curso de Administração da Universidade Regional do Noroeste do Estado do Rio Grande do Sul. <dani.felipim@hotmail.com>.

${ }^{3}$ Aluna do Curso de Administração da Universidade Regional do Noroeste do Estado do Rio Grande do Sul. $<$ kahrouzinha@gmail.com>.

${ }^{4}$ Aluno do Curso de Ciências da Computação da Universidade Regional do Noroeste do Estado do Rio Grande do Sul.<vinirssantos@gmail.com>.

5 Professor do Programa de Pós-Graduação em Desenvolvimento na Universidade Regional do Noroeste do Estado do Rio Grande do Sul - Mestrado (PPGDES/UNIJUÍ). <allebr@unijui.edu.br>.
} 
achievement of this study, it was found that both Coredes showed weaknesses in the preparation of their plans. Similarly, the interviews point to the need to conduct a new regional agreement before to the update of the current plans, if the regions actually want to assume the process and its outcome in all phases, especially in the implementation and effective materialization.

Keywords: Regional Development. Strategic Planning. Social participation. Civil society. Regional Development Councils.

\section{INTRODUÇÃO}

Este estudo é vinculado ao projeto de pesquisa "Estratégias de planejamento e gestão regional no Rio Grande do Sul” em desenvolvimento por uma rede de pesquisadores de programas de Pós-Graduação de universidades gaúchas (PPGDR/Unisc, PPGDES/Unijuí, PROPUR/Ufrgs), com apoio financeiro da Fapergs e do CNPq. Desenvolvido a partir de agosto de 2013, o objetivo do projeto-rede é o de compreender como nos últimos anos tem ocorrido o desenvolvimento das políticas públicas de planejamento regional no Rio Grande do Sul, notadamente a partir do processo de construção e de implementação dos planos regionais de desenvolvimento pelos Conselhos Regionais de Desenvolvimento (Coredes) em suas regiões de abrangência. Objetiva-se também analisar como a sociedade civil e o Estado participaram desses processos, compreendendo inclusive quais são as principais características, particularidades, avanços, dificuldades e limitações apresentadas por esses processos nas regiões de atuação dos Coredes.

Os Coredes foram criados no início da década de 90, no Rio Grande do Sul, com o intuito de articular e propiciar a participação de atores políticos, econômicos e sociais em atividades relacionadas com a promoção do desenvolvimento regional (BANDEIRA, 2011). Uma das suas atribuições legais consiste na elaboração dos planos estratégicos de desenvolvimento das suas regiões de abrangência.

Considerando essa atribuição, é importante verificar como se deu a elaboração dos Planos e qual foi o papel do Estado e da sociedade civil nesse processo. Especificamente, neste subprojeto, foram considerados os casos do Corede Celeiro e do Corede Noroeste Colonial, contribuindo com os objetivos pretendidos no âmbito do projeto-rede ao qual o estudo está vinculado.

Nesse sentido, o objetivo geral deste projeto de iniciação científica foi analisar o processo de elaboração do plano estratégico regional de desenvolvimento dos Coredes Celeiro 
e Noroeste Colonial, descrevendo e analisando a dinâmica de participação da sociedade e do Estado nesses processos. Para tanto, aborda-se a emergência e evolução dos Coredes no Estado, caracteriza-se o Corede Celeiro e o Corede Noroeste Colonial, e analisam-se aspectos do processo de elaboração e gestão do Plano Estratégico de Desenvolvimento desses Coredes.

\section{FUNDAMENTAÇÃO TEÓRICA}

Abordam-se, nesta seção, conceitos acerca do planejamento, aspectos referentes ao surgimento dos Coredes, a caracterização desses Conselhos e a descrição dos elementos metodológicos que orientaram a elaboração dos planos estratégicos dos Coredes.

\section{PLANEJAMENTO}

Segundo Siedenberg e Allebrandt (2010), o planejamento é uma ferramenta de trabalho utilizada para a tomada de decisão e organização de ações de forma lógica e racional, de modo a garantir a realização dos objetivos de uma sociedade, com os menores custos e no menor prazo possível. Miglioli (1982) afirma que o planejamento tem orientação para o futuro, visa objetivos determinados, implica a existência de um sujeito, implica a escolha de caminhos ou ações alternativas e que as ações necessárias para atingir os objetivos têm sequência lógica e são empreendidas de modo organizado.

De acordo com Allebrandt (2011), o planejamento é um processo que compreende duas grandes fases: elaboração, que contempla as fases de conhecimento da realidade e tomada de decisão; e implementação, que engloba as fases de ação e crítica. A etapa de conhecer a realidade compreende um levantamento de informações sobre o território; a decisão refere-se à proposição de transformações para esse espaço; a ação diz respeito à implementação das instruções da etapa de decisão, registradas no plano; e, por fim, a crítica refere-se à avaliação do processo.

O plano é entendido como a sistematização da primeira fase do planejamento, isto é, o relatório da fase de elaboração. Portanto, o plano não pode ser confundido como grande produto do processo do planejamento, pois o resultado desse processo é a concretização dos objetivos traçados durante o processo de planejamento, os quais são registrados no plano (ALLEBRANDT, 2011).

No que se refere ao período dos planos, Miglioli (1982) afirma que, segundo critérios do campo da planificação, o curto prazo compreende um período de até dois anos, o médio 
prazo, três a sete ou nove anos, e o longo prazo, um período superior a sete ou nove anos. $\mathrm{O}$ período depende do tipo de problema para o qual o plano foi elaborado.

O processo de planejamento materializa-se mediante planos, programas e projetos. No entendimento de Siedenberg e Allebrandt (2010), o plano descreve as características gerais, as diretrizes e estratégias políticas de uma ação pretendida, compatibilizando objetivos e metas e servindo de referencial para a elaboração de programas e projetos. Já os programas constituem um aprofundamento do plano, detalhando diretrizes, metas e medidas instrumentais. Por fim, os projetos configuram documentos que sistematizam todos os detalhes da ação que se pretende desenvolver.

\section{SURGIMENTO E CARACTERIZAÇÃO DOS CONSELHOS REGIONAIS DE DESENVOLVIMENTO (COREDES)}

Os Conselhos Regionais de Desenvolvimento (Coredes) foram criados no Rio Grande do Sul, a partir do início da década de 1990, com a missão primeira de serem articuladores da promoção do desenvolvimento de suas respectivas regiões de abrangência. Por outro lado, estes conselhos são também resultado de um processo de descentralização e de crescente participação da sociedade civil organizada na gestão pública (ALLEBRANDT, 2010).

Os processos de participação e a descentralização da gestão pública foram sendo introduzidos na dinâmica da sociedade brasileira de forma gradativa a partir da metade dos anos oitenta do século passado, concomitantemente ao lento processo de redemocratização então em curso no Brasil. Em 1985, depois de mais de 20 anos de regime militar, ocorreram as primeiras eleições para prefeito de Porto Alegre. O prefeito eleito tentou implementar os Conselhos Populares com poder deliberativo. Na gestão seguinte, em 1989, foi implantado o Orçamento Participativo. Estas práticas somaram-se a outras experiências, como a de participação social nas definições das políticas e do orçamento no município de Pelotas, e foram fundamentais para avanços na descentralização da gestão pública, consubstanciadas na Constituição Federal de 1988 e na Constituição Estadual de 1989 (ALLEBRANDT, 2010).

No âmbito estadual, o debate em torno da descentralização e regionalização da gestão pública e do planejamento foi tomando corpo e refletindo-se nos planos e ações dos Governos. Exemplo disso foram o Programa Estadual de Descentralização Regional (PEDR) e o Programa dos Polos Regionais da nova Secretaria Estadual de Ciência e Tecnologia no 
governo Simon (1987-1990). É no contexto desses fatos e mudanças que a Assembleia Constituinte do Estado do Rio Grande do Sul criou novas condições para a regionalização e descentralização da ação governamental ao determinar, conforme disposto no Art. 167 da Constituição Estadual de 1989, que a definição das diretrizes globais, regionais e setoriais da política de desenvolvimento caberá a órgão específico, com representação paritária do governo do Estado e da sociedade civil. Essa diretriz foi incorporada ao Plano de Governo da coligação vencedora das eleições para o governo do Estado em 1990, ao definir que a gestão das políticas públicas seria feita com a participação da população por meio de conselhos regionais de desenvolvimento (ALLEBRANDT, 2010).

A ideia dos conselhos regionais começou a ser operacionalizada a partir de 1991. A equipe do governo eleito desenvolveu estudos para formular uma proposta operacional para os conselhos. Nas regiões, os segmentos da sociedade passaram a se organizar em reuniões preparatórias, buscando apropriar-se do processo e buscando influir na formatação e dinâmica de funcionamento da nova ideia, numa intensa mobilização em seminários que reuniram de duzentas a quinhentas pessoas (ALLEBRANDT, 2010).

Gradativamente o território gaúcho foi sendo organizado em Conselhos Regionais de Desenvolvimento. Em 1991, foram criados 17 Coredes, enquanto em 1994, foram criados mais quatro. Neste ano foi aprovada a Lei Estadual que institucionalizou os conselhos. Em 1996, foi criado o $22^{\circ}$ Corede (Metropolitano Delta do Jacuí), cobrindo desta forma cem por cento do território gaúcho. Em 2002, houve um movimento de fragmentação dos Coredes, com a criação do Corede Alto da Serra do Botucaraí, mesmo contra o posicionamento do Fórum Estadual dos Coredes. Em 2004, foi criado o Corede Jacuí Centro, em 2006, foram criados dois outros Coredes e, em 2008, mais dois Coredes, totalizando a partir de então 28 Coredes no Estado.

De acordo com Büttenbender, Siedenberg e Allebrandt (2011), o desenvolvimento equilibrado e harmônico do Estado a partir do enfrentamento das desigualdades e desequilíbrios econômicos e sociais das regiões sustenta seis objetivos principais dos Coredes: a) a promoção do desenvolvimento regional harmônico e sustentável; b) a integração dos recursos e das ações do Governo e da região; c) a melhoria da qualidade de vida da população; d) a distribuição equitativa da riqueza produzida; e) o estímulo à permanência do homem em sua região; e f) a preservação e recuperação do meio ambiente. Ainda de acordo com estes autores, os Coredes têm constituição jurídica própria em cada região. Entre os 
principais objetivos dos Coredes está o de formular e executar estratégias regionais, consolidando-as em planos estratégicos de desenvolvimento regional. Este entendimento era explicitado pelos Coredes desde o início da década de 90. Entretanto, a maioria dos Conselhos Regionais, ao longo dos anos, não conseguiu dar conta dessas atribuições prioritárias.

O Conselho Regional de Desenvolvimento do Noroeste Colonial (Corede-Norc) foi criado em 1991. Até 2007, era composto por 32 municípios. Uma nova configuração foi estabelecida, a partir de 2008, com o desmembramento do respectivo Corede. Os 21 municípios desmembrados constituíram um novo Conselho, o Corede Celeiro, e a nova configuração do Corede-Norc passou a contar com 11 municípios, sendo eles: Ajuricaba, Augusto Pestana, Bozano, Catuípe, Condor, Coronel Barros, Ijuí, Jóia, Nova Ramada, Panambi e Pejuçara (VALANDRO et al., 1999).

Conforme a FEE (2014), o Corede-Norc tinha uma população de 168.821 habitantes em 2013, uma área de 5.168,1 $\mathrm{km}^{2}$, densidade demográfica de 32,3 hab/km²; a taxa de analfabetismo de pessoas com 15 anos ou mais era de 4,23 \% em 2010; a expectativa de vida ao nascer era de 71 anos em 2000; o coeficiente de mortalidade infantil era de 10,61 por mil nascidos vivos em 2012; o produto interno bruto (PIB) era de 4,4 bilhões de reais e o PIB per capita de R 26.451 (2012); as exportações totais alcançaram 97,2 milhões de dólares.

O Conselho Regional de Desenvolvimento da Região Celeiro abrange 21 municípios: Barra do Guarita, Bom Progresso, Braga, Campo Novo, Chiapetta, Coronel Bicaco, Crissiumal, Derrubadas, Esperança do Sul, Humaitá, Inhacorá, Miraguaí, Redentora, Santo Augusto, São Martinho, São Valério do Sul, Sede Nova, Tenente Portela, Tiradentes do Sul, Três Passos e Vista Gaúcha. Foi criado a partir do desmembramento do Corede Noroeste Colonial em janeiro de 2008 pelo Decreto n ${ }^{\circ} 45.436$, de 09/01/2008.

O Corede Celeiro tinha em 2013 uma população de 140.802 habitantes, área de $4.743,0 \mathrm{~km}^{2}$, densidade demográfica de 29,7 hab $/ \mathrm{km}^{2}$; a taxa de analfabetismo de pessoas com 15 anos ou mais era de 8,55\% em 2010; o coeficiente de mortalidade infantil de 7,80 por mil nascidos vivos (2012), o PIB era de 2,3 bilhões de reais e o PIB per capita de 16.918 reais em 2012; e as exportações totais atingiram o montante de 15,8 milhões de dólares em 2014.

Os Coredes Noroeste Colonial e Celeiro localizam-se no noroeste do Estado do Rio Grande do Sul, na fronteira com a Argentina e com o Oeste do Estado de Santa Catarina. O Corede Noroeste Colonial faz divisa com o Corede Alto Jacuí, Rio da Várzea, Celeiro, Fronteira Noroeste, Missões e Central. A região Celeiro faz divisa com os Conselhos 
Regionais de Desenvolvimento Médio Alto Uruguai, Fronteira Noroeste, Noroeste Colonial e Rio da Várzea. As regiões coredianas podem ser observadas na Figura 1.

Figura 1: Conselhos Regionais de Desenvolvimento (Coredes), Rio Grande do Sul

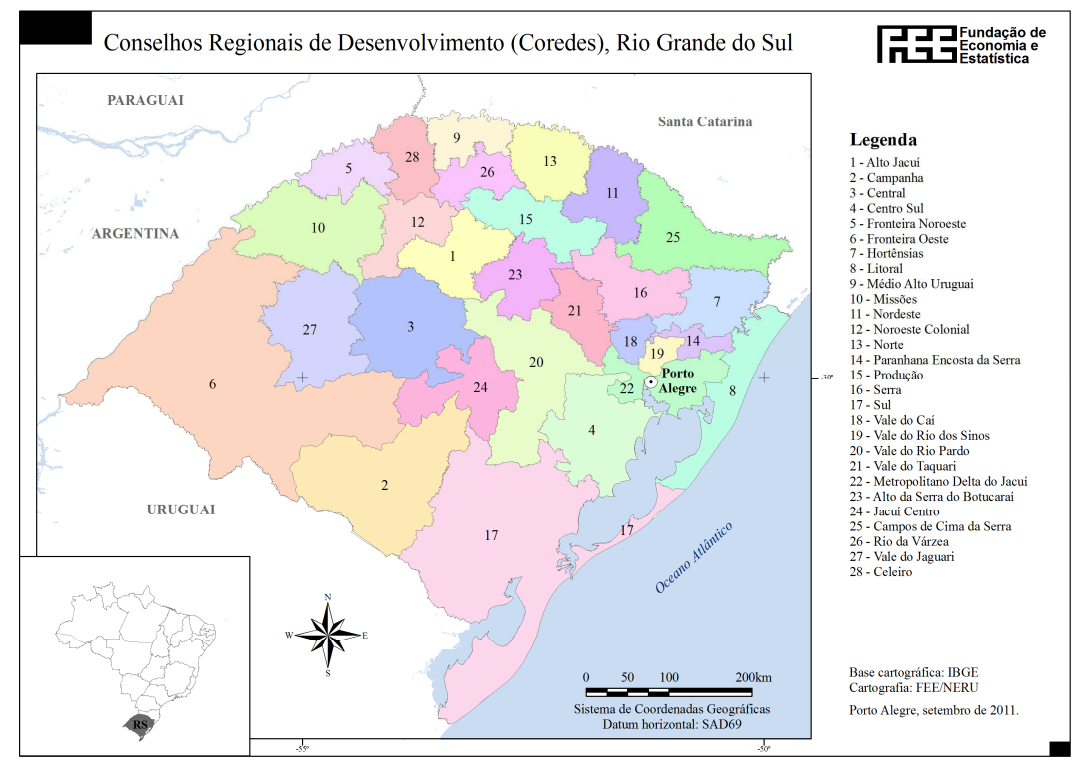

Fonte: Mapas FEE. Disponível em: <http://mapas.fee.tche.br/coredes.html>. Acesso em: 27 fev. 2015.

Segundo o Atlas de Desenvolvimento Humano no Brasil (2013), no Corede Noroeste Colonial, Ijuí apresenta o maior Índice de Desenvolvimento Humano Municipal (IDHM) entre os 11 municípios da região $(0,781)$, seguido de Panambi $(0,761)$ e Ajuricaba $(0,753)$. O município de Jóia apresenta o IDHM mais baixo $(0,686)$.

Na região Celeiro, Três Passos tem o melhor IDHM (0,786), seguido por Vista Gaúcha $(0,757)$ e Santo Augusto $(0,739)$. Já o município de Redentora aparece em último lugar com o IDHM de 0,631, ocupando a posição 3.469 entre os 5.565 municípios brasileiros existentes em 2013. Também com IDHM relativamente baixos aparecem São Valério do Sul, com 0,642 e Esperança do Sul, com 0,661.

O Corede Noroeste Colonial foi o primeiro Conselho Regional a elaborar o seu plano de desenvolvimento logo nos primeiros anos de funcionamento dos Coredes, concluído e publicado em 1994. Nos anos seguintes foi seguido por outros Coredes. No entanto, ainda que alguns Coredes tenham elaborado planos na metade da década de 1990, a maioria dos Conselhos não possuía seus Planos ou estes estavam desatualizados na metade dos anos 2000 . A partir de 2007, o Fórum dos Coredes estabeleceu como meta a elaboração de planos para os 
28 Coredes. Em 2009, o Fórum conseguiu firmar um convênio com o Governo do Estado para viabilizar recursos e condições para a elaboração dos planos. Um Grupo de Trabalho desenvolveu uma metodologia para orientar a elaboração dos Planos, definindo uma metodologia com sete macro etapas para operacionalizar o processo de planejamento (ALLEBRANDT; BUTTENBENDER; SIEDENBERG, 2010).

A primeira destas etapas consta da elaboração do diagnóstico técnico. O desenvolvimento do diagnóstico técnico trata, basicamente, da obtenção de um conjunto de dados quantitativos, explicativos e ilustrativos da realidade local ou regional, subdivididos em sete grandes grupos temáticos, quais sejam: aspectos físico-naturais; aspectos históricos, culturais e institucionais; aspectos demográficos; gestão estrutural; gestão econômica; gestão social e gestão institucional.

A segunda etapa consiste na análise situacional. Esta atividade toma por base os dados brutos do diagnóstico realizado e transforma-os em informações úteis para todos os interlocutores do processo de planejamento por meio de textos e gráficos ilustrativos. É neste momento que se realizam seminários para que os cidadãos e entidades possam validar os dados do diagnóstico técnico, modificando-o, se necessário.

Após, realiza-se a matriz FOFA ou análise SWOT, que objetiva determinar as Forças (strength), Oportunidades (opportunities), Fraquezas (weakenesses) e Ameaças (threaths). O objetivo nesta terceira etapa é apontar as principais potencialidades, limitações, riscos e desafios locais e/ou regionais.

Juntamente com a matriz FOFA, outra etapa importante no processo de planejamento territorial consiste na definição e explicação de diretrizes ou referenciais estratégicos relacionados a uma visão do município ou região almejada. Considera-se que os ganhos decorrentes da discussão fomentada entre os cidadãos e sua explicação num compromisso formal não são apenas simbólicos ou intangíveis.

A quinta etapa é a elaboração dos macro-objetivos, isto é, alvos ou resultados pretendidos pela sociedade, definidos através de um pacto sócio territorial preestabelecido. Considera-se que o ponto crucial de todo e qualquer processo de planejamento consiste na elaboração de instrumentos de ação, ou seja, na determinação de macro-objetivos de desenvolvimento socioeconômico local/regional.

Além do plano de desenvolvimento propriamente dito, outro instrumento é o chamado modelo de gestão de plano (sexta etapa), ou seja, uma arquitetura organizacional 
adequada e responsável pela implementação, atualização e manutenção do plano. O modelo de gestão descreve o sistema institucional, os mecanismos de gerenciamento dos projetos e ações e, como tal, deve ser compatível com a concepção geral e com os princípios do planejamento.

As etapas derradeiras do processo de planejamento estratégico territorial propriamente dito dizem respeito à divulgação, implementação, gestão e revisão do Plano de Desenvolvimento. Para que o processo de planejamento traga resultados concretos, tais etapas não podem ser menosprezadas.

Estas macro etapas formam uma sequência logicamente encadeada e sua operacionalização é decorrência de uma série de atividades que necessitam ser desenvolvidas, preferencialmente, por pessoal técnico capacitado de cada região ou localidade.

\section{MATERIAIS E MÉTODOS}

Este trabalho enquadra-se como pesquisa interpretativa e qualitativa que se preocupou em resgatar e analisar o processo de elaboração do plano estratégico regional de desenvolvimento do Corede Celeiro e do Corede Noroeste Colonial, descrevendo e analisando a dinâmica de participação da sociedade civil e do Estado nesse processo, desde o planejamento, o acompanhamento na execução, até a avaliação dos resultados. Como estratégia metodológica, foi realizada uma pesquisa bibliográfica enfatizando os aspectos teóricos, a caracterização do Corede Celeiro e do Corede Noroeste Colonial, a utilização de três instrumentos de análise, sendo duas check-list com 11 e 36 questões, respectivamente, para enquadramento do processo e do plano, e entrevistas com dirigentes dos Coredes em estudo e agentes políticos e atores sociais da região, com base em roteiro semiestruturado de 21 questões.

\section{RESULTADOS}

Num primeiro momento, realizou-se análise preliminar do Plano Estratégico do Corede Celeiro e do Corede Noroeste Colonial, com base na check-list elaborada no âmbito do projeto-rede. Esta check-list continha onze questões: 1) o plano apresenta algum tipo de diagnóstico econômico suficientemente desenvolvido; 2) o plano apresenta algum tipo de diagnóstico social suficientemente desenvolvido; 3) o plano foi desenvolvido com auxílio de uma consultoria externa; 4) o plano explica de forma clara e detalhada a metodologia de 
desenvolvimento adotada na sua elaboração; 5) o plano traz adequada e suficiente caracterização do histórico e dos municípios componentes do Corede; 6) o plano apresenta e explica a Matriz FOFA - Forças, Oportunidades, Fraquezas e Ameaças; 7) o plano apresenta uma matriz de potencialidades; 8) o plano apresenta uma matriz de priorização de projetos; 9) o plano apresenta análise de cenários para cada área temática contemplada, apoiando-se no diagnóstico; 10) há evidências de que houve alto grau de participação de múltiplos atores na elaboração do Plano; e 11) de forma geral, o plano é abrangente e conciso na descrição dos dados que apresenta.

Esta check-list, aplicada ao Corede Noroeste Colonial, evidenciou que o processo de planejamento e o plano de desenvolvimento do conselho atendeu positivamente todos os onze quesitos. O Corede Noroeste Colonial também foi o único dos 28 Coredes que foi avaliado positivamente em todos os quesitos. Esse enquadramento evidencia que o Conselho conseguiu implementar um processo de planejamento e o respectivo resultado, o Plano, de forma qualificada. Já no caso do Corede Celeiro, os resultados apontam para o fato de que o processo e o Plano apenas atenderam positivamente as questões 4, 7, 8 e 10, portanto, menos da metade das questões definidas.

Para dar mais consistência ao estudo, foi elaborado pela equipe do projeto-rede um segundo instrumento de análise. Tratou-se de um questionário tipo Likert unipolar de cinco opções ( 0 a 4 , em que a opção 4 se aproximava mais do atendimento da metodologia e princípios estabelecidos para o processo de planejamento) com 36 questões. O questionário foi organizado em dois blocos: o primeiro, com 25 questões, abordou elementos do diagnóstico do Plano Estratégico de Desenvolvimento e o segundo, com 11 questões, abordou o Plano Estratégico em si, sua metodologia e elaboração.

O Corede Noroeste Colonial apresentou como resultados o enquadramento na opção zero (0) em 18 questões (50\%), na opção 1 em oito questões, na opção 2 em seis questões e na opção 3 em quatro questões (11\%), não tendo, portanto, nenhuma questão enquadrada na opção 4. Isso evidencia que, mesmo que muito bem avaliado no instrumento básico, ao aprofundar a análise com questões mais detalhadas, o Corede também apresentou muitas fragilidades no processo e no Plano, apresentando avaliação zero em metade das questões. Ainda assim apresentou uma posição razoável na comparação com os demais conselhos. O Corede Celeiro apresentou como resultados o enquadramento na opção zero em 21 questões, a opção 1 em oito questões, na opção 2 em seis questões e na opção 3 em apenas uma questão. 
O terceiro instrumento para a análise foi a realização de entrevistas com base num roteiro semiestruturado de 21 questões. As percepções de dirigentes e ex-dirigentes evidenciaram a importância fundamental da elaboração de Planos de Desenvolvimento para os avanços da sociedade numa perspectiva de democracia deliberativa.

As entrevistas realizadas apontaram que no processo de elaboração do Plano Estratégico de Desenvolvimento do Corede-Norc e do Corede Celeiro houve participação de representantes da sociedade civil e de instituições em seminários municipais e regionais. Os entrevistados afirmaram que os participantes foram organizados em grupos por setor/segmento ao qual eram vinculados, como, por exemplo, na área de saúde. Aos grupos, foi apresentado o diagnóstico técnico da região e foi possibilitada a discussão acerca do levantamento de dados. Nesses seminários, houve a possibilidade de discussão e proposição de projetos para compor os Planos de Desenvolvimento dos Coredes em estudo. Os seminários eram abertos e realizados com as principais lideranças. Os presidentes ou integrantes dos Comudes eram os responsáveis pela organização dos seminários locais e pela articulação das lideranças para a participação no processo.

No caso do Corede Noroeste Colonial, um dos entrevistados explicou que esses seminários foram realizados com todos os municípios da região de abrangência deste Corede, com exceção de dois municípios que não quiseram realizar esses encontros. Entrevistados afirmaram que em alguns municípios houve baixa participação dos empresários, como, por exemplo, no município de Ijuí. Já o município de Panambi integrou o maior número de participantes no seminário local. No que se refere à participação de movimentos sociais, sindicatos e trabalhadores, um dos entrevistados afirmou que houve participação em alguns locais, como Jóia, Panambi, Ajuricaba e Ijuí.

Considerando o caso do Corede Celeiro, um dos entrevistados mencionou que a região foi dividida em microrregiões onde aconteceram as reuniões. Ele acrescenta que houve mais de trinta reuniões no processo de construção do Plano e que nestas houve participação da comunidade, de diversas entidades, de vereadores e dos Comudes, tendo, no entanto, pouca participação dos prefeitos. Um dos entrevistados afirmou que houve dificuldades na elaboração do diagnóstico técnico do respectivo Corede, mas houve preocupação em conhecer a realidade de cada município.

Para a construção dos planos de desenvolvimento nestes Coredes foram utilizados aspectos da metodologia do Instituto Latinoamericano de Planificación Económica y Social 
(Ilpes) ${ }^{6}$ e aspectos da metodologia criada pelo Grupo de Trabalho. Para um dos entrevistados a metodologia Ilpes era boa, porém tinha algumas restrições, o que resultou na necessidade de se fazer algumas adaptações para a elaboração dos planos.

Segundo entrevistados, o maior desafio a ser enfrentado pelos Coredes diz respeito ao gerenciamento dos planos de desenvolvimento. Entendem que os planos poderiam ser mais utilizados, que há falhas na sua execução e que deveria existir uma maior cobrança em relação aos órgãos públicos e aos políticos e candidatos para que os planos se transformem efetivamente em ações. Alguns entrevistados entendem que não há um alinhamento entre os projetos prioritários dos Coredes e as demandas definidas nas Consultas Populares realizadas anualmente com vistas à inclusão de projetos de interesse regional nos orçamentos do estado gaúcho.

A partir da análise documental, identificou-se o registro de 31 reuniões no Corede Noroeste Colonial no período de outubro de 2009 a abril de 2010, incluindo reuniões sobre o planejamento estratégico do Corede, reuniões da equipe de trabalho e assessoria metodológica e registro de três seminários regionais. Considerando apenas o caso das reuniões que tiveram o seu horário de início identificado em suas listas de presença, a maioria das reuniões aconteceu pela parte da manhã, mas também houve reuniões nos outros turnos. O número de presentes variou de 3 a 31 pessoas por reunião.

Já no caso do Corede Celeiro, identificou-se a realização de dezoito reuniões no período de agosto a outubro de 2010, incluindo reuniões sobre o planejamento estratégico do Corede, reuniões da equipe de trabalho, reunião de apresentação da metodologia para elaboração do plano, reuniões setoriais, reunião do grupo gestor e micro seminários. Apenas duas reuniões não possuíam o horário de início identificado em suas listas de presença, sendo que a maioria das reuniões aconteceu pela parte da manhã. O número de presentes variou entre 4 a 61 pessoas.

Ambos os Coredes apresentaram fragilidades no processo de elaboração dos seus planos. Da mesma forma, as entrevistas apontam para a necessidade de realização de um novo pacto regional antes da atualização dos atuais planos, se efetivamente quiserem assumir o processo e o seu resultado em todas as suas fases, especialmente na de implementação e efetiva concretização.

\footnotetext{
${ }^{6}$ O Fórum dos Coredes, com apoio do Ministério da Integração Nacional e do Governo do Estado viabilizou a contratação do Ilpes para realização de curso de formação em planejamento local para técnicos dos 28 Coredes.
} 


\section{CONCLUSÃO}

Os Coredes surgiram no início da década de 90 no Rio Grande do Sul visando propiciar a participação de agentes políticos e econômicos e atores sociais na promoção do desenvolvimento regional. Uma das suas atribuições consiste na elaboração de planos estratégicos de desenvolvimento das suas regiões. Ainda que diversos Coredes tenham elaborado planos de desenvolvimento na década de 1990, é apenas em 2009 que os conselhos viabilizam um convênio com o governo estadual, possibilitando que os 28 Coredes elaborassem seus respectivos planos de desenvolvimento. Dado a importância deste fato, o presente estudo buscou conhecer e compreender os processos de elaboração desses planos nos Coredes Celeiro e Noroeste Colonial, visando descrever e analisar aspectos da dinâmica de participação da sociedade civil, do mercado e do Estado nesses processos.

As análises apontam que os Coredes Noroeste Colonial e Celeiro tiveram seus planos estratégicos de desenvolvimento elaborados de forma participativa e que houve discussões e definição de propostas por parte de lideranças presentes nos seminários que ocorreram nos municípios integrantes dos Coredes. Para a construção dos planos, foram utilizados aspectos da metodologia Ilpes e da metodologia elaborada pelo Grupo de Trabalho do Fórum dos Coredes. Os resultados apontam também que um dos maiores desafios das regiões está no gerenciamento desses planos, isto é, não basta elaborar planos de forma participativa se depois disso os mesmos são esquecidos ou se não há condições efetivas de implementá-los.

Sendo assim, os Planos Estratégicos de Desenvolvimento dos Coredes Noroeste Colonial e Celeiro necessitam de uma avaliação séria por parte dos agentes públicos, empresários e atores sociais que participam do processo, no sentido de garantir que a região avance mais no debate da promoção do desenvolvimento. Neste sentido, é fundamental que seja feito um melhor estudo dos planos por parte dos gestores e que se tenha um articulador junto ao município e aos Coredes para que as propostas se transformem em ações. É fundamental que os gestores conheçam os aspectos explicitados nos planos e compreendam que este foi elaborado para gerar um compromisso entre a sociedade e o poder público, pois é imprescindível o comprometimento de todos os envolvidos na execução das propostasprojetos resultantes deste processo.

Estado, mercado e sociedade civil atuando de forma articulada são elementos chave no processo de desenvolvimento das regiões. A trajetória dos Coredes demonstra que a atuação da sociedade civil organizada é fundamental para estabelecer mudanças na gestão das 
políticas públicas. A existência de processos de planejamento e a elaboração de planos de desenvolvimento são fundamentais nesta dinâmica.

No entanto, há necessidade de avanços qualitativos nos processos de planejamento e, em especial, na execução dos planos elaborados e acordados pelos participantes. Além disso, é preciso construir pactos regionais para que os diferentes agentes e atores assumam os planos aprovados, considerando-os nos outros espaços e dinâmicas de debate dos problemas e alocação de recursos públicos, como no caso da elaboração dos planos plurianuais e dos orçamentos dos municípios, das consultas populares visando o orçamento estadual e até mesmo a inserção de projetos e demandas nos orçamentos federais.

\section{REFERÊNCIAS}

ALLEBRANDT, S. L. Planejamento governamental e planejamento regional: alguns conceitos básicos. PPGDES/Unijuí: Caderno de Pesquisa 23, 2011.

ALLEBRANDT, S. L. Cidadania e gestão do processo de desenvolvimento: um estudo sobre a atuação dos conselhos regionais e municipais de desenvolvimento do Rio Grande do Sul, de 1990 a 2009. Santa Cruz do Sul, 2010. 302 p. Tese (Doutorado), Programa de Pós-Graduação em Desenvolvimento Regional, Universidade de Santa Cruz do Sul, 2010.

ALLEBRANDT, S. L.; BUTTENBENDER, P. L.; SIEDENBERG, D. R. Detalhamento de um modelo de planejamento estratégico territorial. In: SIEDENBERG, D. R. (Org.). Fundamentos e técnicas de planejamento estratégico local/regional. Santa Cruz do Sul: Edunisc, 2010. p. 49-79.

BANDEIRA, P. S. Uma experiência de institucionalização de regiões no Brasil: Os Coredes do Rio Grande do Sul. In: DALLABRIDA, V. R. (Org.). Governança territorial $e$ desenvolvimento: descentralização político-administrativa, estruturas subnacionais de gestão do desenvolvimento e capacidades estatais. Rio de Janeiro: Garamond, 2011. p. 212-253.

BÜTTENBENDER, P. L.; SIEDENBERG, D. R.; ALLEBRANDT, S. L. Coredes: estruturação, articulações intra e inter-regionais, referenciais estratégicos e considerações críticas. In: DALLABRIDA, V. R. (Org.). Governança territorial e desenvolvimento: descentralização político-administrativa, estruturas subnacionais de gestão do desenvolvimento e capacidades estatais. Rio de Janeiro: Garamond, 2011. p. 311-338.

MIGLIOLI, J. Introdução ao planejamento econômico. São Paulo: Brasiliense, 1982.

ATLAS DE DESENVOLVIMENTO HUMANO NO BRASIL. Disponível em: http://www.atlasbrasil.org.br/2013. Acesso em: 27 fev. 2015. 
SIEDENBERG, D. R.; ALLEBRANDT S. L. Fundamentos do planejamento. In: SIEDENBERG, D. R. (Org.). Fundamentos e técnicas de planejamento estratégico local/regional. Santa Cruz do Sul: EDUNISC, 2010. p. 29-48. 